\title{
A Systematic, Holistic and Integrative Process of Self-Control for Voicing with Optimal Coping Effects in Teachers. 1. A Process of Awareness - An Expert's Opinion
}

\author{
Magda J.M. Carola Van Opstal \\ Practice Vocal Communication and Speaking Arts Performance, Leuven, Belgium
}

\section{Key Words}

Process of awareness $\cdot$ Coping skills $\cdot$ Stress $\cdot$ Learning

process $\cdot$ Teacher's voice $\cdot$ Emotion

\begin{abstract}
A learning strategy is presented for eustress-euvoicing, which prevails over distress-disvoicing. It is based on the understanding of the mechanisms of stress-voicing, conceived as a dynamic circular process of interacting entities, i.e. stressors/signals-arousal/activation-emotion-coping-effects (SAECE), which is the rationale for a multidisciplinary approach in coaching professional voice users. A systematic, holistic and integrative process of self-control (SHIPS) is directed by functional analysis and consists of awareness and change. Emotion, a mixture of appraisal, affect and movement, is the pivot in SHIPS. SHIPS with (student) teachers aims at the competence of voicing (V) in an optimal (O) way of coping $(C)$, which means vocal communication that is effective $(E)$ to meet a balance in physical, interpersonal and existential wellness when responding to demands and challenges in the individual teacher's ( $T$ ) field of communication (VOCE-T). The process of awareness intends to understand the course of multiple interactions in SAECE that condition eustressors and distressors related to (non)-integrated coping. The (student) teacher and coach are conscious and ac-
\end{abstract}

tive participants in the process of awareness that is dynamic and evolving and aims at the preparedness to change nondesirable habits and skill modes into VOCE-T.

Copyright $\odot 2010$ S. Karger AG, Basel

$$
\begin{array}{r}
\text { The field of therapy and its many facets } \\
\text { needs anything but another closed system } \\
\text { A.A. Lazarus (1968) } \\
\text { Evidence based practice is the integration } \\
\text { of best research evidence with } \\
\text { clinical expertise and patient values } \\
\text { Institute of Medicine [1; p. 147] }
\end{array}
$$

\section{Introduction to a Systematic, Holistic and Integrative Process of Self-Control as a Process of Awareness}

Stress in voice (stress-voicing) is an important feature in optimal vocal communication. Thinking in an interdisciplinary way leads to a common view on problem analysis of the teacher's stress in voicing. Multimodel concepts are basic to the learning strategy of a systematic, holistic and integrative process of self-control (SHIPS).

\section{KARGER \\ Fax +4161306 1234 \\ E-Mail karger@karger.ch}

www.karger.com
(C) 2010 S. Karger AG, Basel

1021-7762/10/0622-0061\$26.00/0

Accessible online at:

www.karger.com/fpl
M.C. Wellens-Van Opstal

A. Delaunoislaan, 15

BE-3001 Heverlee-Leuven (Belgium)

Tel. +32 16235050

E-Mail magda.van.opstal@gmail.com 
They imply cognitive-behavioural approaches [2-21]. The coaching of professional voice users toward self-control is the main aim of SHIPS. A multidisciplinary model could serve as a working hypothesis in the assessment of biopsychosocial human communication regarding the individual's reaction pattern in eustress and euvoicing versus distress and disvoicing. Wellens and Van Opstal $[22,23]$ have proposed a comprehensive dynamic model of how stress affects voice with fluctuations in daily life and along the stages in life. In this model a holistic-analytic approach has shown to be appropriate.

Stress-voicing is considered as a whole that is made up of dynamic conditions and events. These conditions and events are ordered into 5 entities: stressors/signals, arousal/activation, emotions, coping and effects (SAECE). The way these entities interact is conceived as functional relationships in a circular process. In this circular process, emotion, defined as a mixture of apprais$\mathrm{al}$, affect and movement, is the pivot. Around this pivot, stressors/signals, arousal/activation, coping and effects show a mutual and dynamic interaction [22]. Each entity forms patterns of conditions and events. In the SAECE model, the functional relationships constitute the biopsychosocial characteristics and potentials of the voicing individual. This understanding is the key for opening a view on how specific autonomic and motor neural aspects in interaction with cognitive aspects of emotion have been developed and are maintained [2, 3, $14,16,19,22,23]$. Awareness or understanding of the mechanisms of SAECE is essential for the trainee's insight in biological and mental excitement in stress-voicing (table 1) [23]. The accumulation of too high biological arousal and too intense mental activation prompts the teacher to be intensively distressed and vocally disrupted [22, 23]. In high excitement, neurobiological functions are selectively inhibited or become hyperactive; motor or cognitive functions are directed to (over)adaptive or defensive acts [23, 24].

The entities stressors/signals, arousal/activation, emotions, coping and consequently effects of the SAECE model can be modified $[5,6,21,25]$. Subsequently, these modified entities should be integrated systematically. Modification and integration make up the process of change. The SAECE model is the rationale of awareness and of change. Functional analysis is a tool for the organization of mechanisms of SAECE, applied in individual stress-voicing and decision making. Ordering and decision making is a dynamic repetitive process $[10,11,15,20,26]$.

\section{Teachers in a Process of Awareness}

Teachers are representatives of the most obvious and demanding professional voice users. In these voice users, high criteria for adapted voicing have to be met $[22,23$, 27-29].

In the care and cure of the (student) teacher's voice, a multidimensional approach is indicated in many cases. Apart from medical and organizational interventions, adaptation of the teacher's voice should be enhanced by voice training or therapy $[22,23,30]$. Self-regulation of trait stress is highly facilitative for the prevention of state stress. This means that consistent conditions, the memory and the anticipation of effects (trait) of the voicing behaviour colour the teacher's actual feeling about his/her modes of coping and state control. In turn, self-regulation of state stress is basic to adapted communication skills, e.g. by relaxation and breathing exercises. In selfregulation, emotion is central. Emotion has a central function in the competence of adapted vocal communication [22, 23]. Self-regulation of emotion and adapted vocal communication imply specific coping skills. These coping skills should be adapted to the whole of the complex communication environment in order to be able to meet the teacher's communication needs. In these perspectives, a learning process plays a central role in the multidimensional approach of stress-voicing. Principles of learning govern the mutual reinforcing influences within and between the entities of SAECE. Methods for modification of behaviour are substantiated by these same principles $[12,19,25,31]$. Therefore, principles of learning rule stress-voicing management.

Awareness refers to understanding of the mechanisms of the possible etiological factors and the factors that influence the course of the problem. Awareness of the trainee is created which is basic to the modification of entities and the subsequent voicing management. Change is the process of development of desirable habits and enlarged skills. Awareness and change are a twin process. This twin process aims at a gradual growth of aptness to selfcontrol. This results in eustress-euvoicing prevailing over distress-disvoicing.

The modification and integration of the entities stressors/signals, arousal/activation, emotions, coping and effects are targeted and executed step by step. This way of processing is called 'systematic'. The 'holistic' feature of the process refers to the context of SAECE. In the learning strategy of SHIPS, the development of awareness of the power of free choice is crucial. Self-control is considered to be the working agent for subsequent and ongoing 
Table 1. The interaction of biological and mental excitement in stress voicing after Wellens and Van Opstal [22, 23]

\begin{tabular}{|c|c|}
\hline Primary excitement & Secondary excitement \\
\hline $\begin{array}{l}\text { Autonomic aspects } \\
\text { Muscular tension increases }\end{array}$ & $\begin{array}{l}\text { Headache } \\
\text { Neck and shoulder pain }\end{array}$ \\
\hline Heart and respiration rate increases & $\begin{array}{l}\text { Heart palpitation } \\
\text { Changes in rate and depth of respiration } \\
\text { Hyperventilation }\end{array}$ \\
\hline $\begin{array}{l}\text { Reduced range of perception, tunnel vision } \\
\text { Pupils change size, field of vision narrows }\end{array}$ & Attention sharply and narrowly focused on stressor \\
\hline Mucus/saliva production decreases & $\begin{array}{l}\text { Swallowing feels difficult } \\
\text { Dry mouth and throat } \\
\text { Throat is getting tight } \\
\text { Throat clearing }\end{array}$ \\
\hline Visceral reflexes & $\begin{array}{l}\text { Nausea, diarrhoea } \\
\text { Gastric acid production } \\
\text { Urinary urgency }\end{array}$ \\
\hline Sweating increases & Palms feel cold and sweaty \\
\hline Vasoconstriction & $\begin{array}{l}\text { Complexion becomes pale } \\
\text { Syncope } \\
\text { High blood pressure }\end{array}$ \\
\hline $\begin{array}{l}\text { Metabolic, endocrine functions increase: } \\
\text { catecholamines, ACTH, cortisone }\end{array}$ & $\begin{array}{l}\text { Positive feeling of 'being pumped up' } \\
\text { Negative feeling of 'being exhausted' }\end{array}$ \\
\hline $\begin{array}{l}\text { Motor aspects } \\
\text { Increased muscle tension }\end{array}$ & Alteration in voicing and singing \\
\hline Motor (dys)co-ordination, trembling & $\begin{array}{l}\text { Hoarseness } \\
\text { Tremor } \\
\text { Restricted frequency range, prosody, intensity, dy- } \\
\text { namics } \\
\text { Resonance: poor harmonics } \\
\text { Articulation problems } \\
\text { Phonofatigue, phonodiscomfort } \\
\text { Poor relaxation, posture, breath support, acting, etc. } \\
\text { Psychomotor agitation } \\
\text { Muscular tensioning } \\
\text { Affected acting, etc. }\end{array}$ \\
\hline $\begin{array}{l}\text { Cognitive aspects } \\
\text { Mental activity increases }\end{array}$ & $\begin{array}{l}\text { Heightened vigilance, awareness } \\
\text { Sleep pattern changes } \\
\text { Impaired memory and concentration }\end{array}$ \\
\hline $\begin{array}{l}\text { Appraisal of stimuli, arousal and activation } \\
\text { predisposed by: expectancy, perceptual selectivity, } \\
\text { concepts, imagination, previous experiences }\end{array}$ & $\begin{array}{l}\text { Pleasure/displeasure } \\
\text { Labelling: indifference, basic interest, surprise, fear } \\
\text { Emotions } \\
\text { Feeling of being 'mentally prepared' } \\
\text { Feeling of being 'burned out' }\end{array}$ \\
\hline
\end{tabular}


change $[22,23,32-34]$. By self-control the twin process of SHIPS results in a positive feedback loop of stress-voicing. Functional analysis is basic to the systematic and holistic features of SHIPS as a process of awareness and change. Through functional analysis, the multiple interactions within and between the entities of SAECE are assessed in view of change. It results from the fact that SHIPS intends to enhance interrelated aspects in eutress-euvoicing. In a systematic way, they reinforce each other in an ongoing process of facilitation, modification and generalization. Consequently, functional analysis is a guiding mechanism for both coach and trainee in SHIPS.

The aim of change is to obtain a habit of voicing (V) in an optimal way $(\mathrm{O})$ of coping $(\mathrm{C})$ to meet basic needs effectively (E) in the teachers' field ( $\mathrm{T}$ ) of communication (VOCE-T). All the features of SHIPS are considered to be prerequisites for long-lasting results in VOCE-T.

The aim of this paper is to describe the learning process of awareness of the multiple interactions of SAECE by application of SHIPS. The process of awareness within the general framework of SHIPS is dynamic and evolving. Awareness must be present in both the caregiver and trainee, who are partners in a growth process. Awareness has features of both a systematic and holistic process. These features are described in this paper.

Examples from case reports and self-reports that are illustrative to the text and/or that contribute to the comprehension of it have been inserted in what follows.

\section{Awareness of the Course of Multiple Interactions in SAECE}

Functional analysis provides systematic insight into how a person's characteristics of stress and voicing coincide with the entities of SAECE. Table 1 is a useful tool for it $[22,23]$.

The entities of SAECE are in a continuous dynamic interaction. There should be an understanding of which function the various aspects of voicing have in the whole of the individual SAECE process. Systematic awareness, however, should not be understood as an aim in se that is attained separately from the course of the process of change in SHIPS. Systematic awareness runs like a continuous thread through SHIPS. It is promoted by several practical methods and devices that are used, depending on the individual trainee's program throughout the development to VOCE-T. Among these are information and exchange at conversations in individual and/or in group settings, experience-based reporting, exercises on sensi- tivity for relevant and consistent criteria of(self)judgment, vicarious and self-observation, and paper-and-pencil tests. Sessions for exploration, for rehearsal and for application may apply in vitro or in vivo, in verbal modelling, in role playing and in homework. Continuous updates of the functional relationships need to be provided by functional analysis during the whole process of SHIPS. This procedure gradually results in deepened awareness in the SAECE holism.

For example Carl reports: 'It was only after learning about SAECE and realizing that I have a choice in HOW I use my voice to communicate that I could start to heal all of the abusive voice techniques I have accumulated in my career. Learning about SAECE and experiencing during the therapy what eustress and euvoice should feel like was a real eye-opener for me and a motivation to work on techniques to change and "peel off" all of the accumulated bad habits.

Awareness or understanding of the mechanisms of SAECE is essential for the trainee's insight into biological and mental excitement in stress-voicing (table 1) [22, 23]. In the SAECE holism, emotion is central in the complex of the dynamic of interactions. Three observable response systems in emotion are interactive in SAECE. These response systems are autonomic neural reactions, verbalcognitive behaviours and motor acts [16].

Emotional apprehension of internal and external stressors is related to values of survival and physical wellness, interpersonal rewards, creativity and existential fulfilment. Interest, enjoyment, surprise, sadness, anger, disgust, contempt, fear, shame, shyness and guilt can be distinguished as fundamental emotions, each of which has distinct properties. Both the coach and trainee recognize and differentiate facial, vocal, gestural and postural modes of expression. The trainee is becoming more and more conscious that these modes of expression are behavioural components of emotion as a motive. These behaviours are distinguished from the acts that follow affective states $[2,3,14]$. Voicing as a coping act deals with opportunities, challenges and dangers to basic human needs $[22,23]$.

For example Carl reports: 'In my case, it was a change in my personal situation (divorce) that led me to seek voice therapy. All of a sudden I started to have more and more problems with voicing. By learning about SAECE and the pivotal role of emotion, I realized that many of the "bad habits" I had accumulated over the years find their origin in some sort of emotional reaction. My divorce was just the catalyst to this process of discovery. In this respect voicing is a way of emotional expression that is distinguished from voicing as a coping act.'
Van Opstal 
In stress-voicing, physiologic, verbal-cognitive and motor aspects work in an interactive way. This understanding is the key for opening a view on how the individual's specific autonomic and motor neural aspects in interaction with cognitive aspects of emotion and voicing have been developed and are maintained. Neurobiological functions are either selectively inhibited or become (hyper)activated; motor or cognitive functions are directed to (over)adaptive or defensive acts [24].

An adequate level of stress is called eustress [22, 23, 35]. Eustress provides the desired amount of energy and has the basic mood of joy. Eustress facilitates channelling of energy, sharpens the intellect and influences the coordination of voicing actions [14]. Eustress is considered as a favourable condition for VOCE-T. An inadequate level of stress (distress) is too long, too intense, or too local. It means that when exceeding a 'critical' threshold the level of arousal/activation does not return spontaneously or easily to a moderate or rest level. This 'critical' threshold is variable from individual to individual [22-24]. In SHIPS the stressors that function as either eustressors or distressors are identified. This leads to the awareness of situations of accumulation of high biological arousal and intense mental activation that prompts the teacher to be intensively distressed and vocally disrupted $[22,23]$.

'Trait stress' and 'state stress' in SHIPS are linked to change of arousal that is associated with change of affect. It comprises change of the internal and external environment [14]. The basic mood that is combined with persistence of relatively increased biological arousal and mental activation is called 'arouseness' or 'trait stress' [22-24, $36,37]$. The affect and the activation level evoked at momentary apprehension of stimuli is called 'state activation' or 'state stress'. Increased trait stress is supposed to be a facilitator of proneness to increased state activation. The anticipation of (not)responding properly and affective evaluation in the field of communication are likely associated. Trait stress and state stress accumulate [36].

For example Carl reports: 'For me, the clearest example of this is the field trips we took. Often my voice was already less than optimal before the trip, just in anticipation of the challenging conditions (e.g. large group, bad acoustics, long days) that would await during the trip'.

The general level of increased arousal may become manifest as a 'critical' antecedent when it is accumulated with a moderate increase of the state stress in an acute speaking situation. The accumulation of high biological arousal and intense mental activation prompts the teacher to be intensely distressed and vocally disrupted [22, 23, 38, 39].

Awareness in Self-Control for Voicing with Optimal Coping Effects in Teachers
For example Carl reports: 'The end of September and some time around February are usually a time of great stress and problems with the voice. Often these are times with high demands on teacher's time (with reports to be written, much grading to be completed, parent meetings to prepare, students that are getting more rowdy, increasing demands from director and administration, etc.). Often it is that feeling of not being able to cope that leads to (mental and physical) fatigue, which in turn then leads to overstretching one's resistance and voice. It would be very interesting to compare this subjective observation to statistics of teacher absences for medical reasons or doctor's observations about the times of year when they see most teachers.'

If 'critical' antecedents are too frequent or too long, the habitual level of stress is likely to be kept near the critical level [24]. With respect to VOCE-T, circumstances are critical when they push the ability to adapt to physical, mental and vocal load to a limit. The highly enthusiastic and multiple-skilled teacher has to be aware of this.

Emotional apprehension of stimuli is the cognitive aspect of stressors $[2,14,40]$. In essence, emotional apprehension is connected with different levels of needs (safety, security, creativity) which are inherent to the human condition [17, 18, 22, 23, 34, 37]. The whole of stress-voicing in the teacher's communicational environment has to be explored regarding safety, security and creativity. In the context of VOCE-T, safety concerns the condition and the use of the vocal apparatus to be beneficial to its health and/or to the feeling of comfort. In vocal communication, security concerns the use of the voice as an interpersonal act for coping with needs such as affection, recognition, and being popular. Voicing effectively also concerns the teacher's need for charisma. This means the need to be estimated as an educator, an instructor, an advisor, an organizer, a public speaker, a deliberator, a mental leader [38, 41-43]. On the level of creativity, the voice is used as a creative act and as a means of spiritual exchange. Being a teacher has the aura of a vocation. The teacher's voice is felt as a tool for existential fulfilment. On the existential level, the effect of voicing is to give shape to self-exceeding in serving the others and 'The Other' $[22,23,34,42]$. Emotion provides the vital energy inherent to the material, social and spiritual bases of stress in human beings [14, 24]. (Dis)harmony in effects on basic levels of needs produces effects on each specific level [22-24]. Any harm to voicing on one or more of these levels may lead to illness and reduced motivation [14, 22-24, 43-48].

A diversity of stimuli in the internal or external environment, associated with perceived needs is apt to function as signals [2]. 'Signals for needs' indicate either opportunities and challenges or dangers to effectively meet

Folia Phoniatr Logop 2010;62:61-70 
the basic needs. This means signals can act as eustressors and distressors on the different levels of needs. Through conditioning, signals have the potential to evoke interest going either to enthusiasm or to fear [14]. In SHIPS, this kind of probabilities in the trainee is checked by the procedure of functional analysis. The (student) teacher as a trainee in SHIPS becomes more conscious of these incentives in relation to coping effectively and harmoniously on different basic areas of well-being. By the dynamic of functional analysis, the teacher discovers stimuli that function as signals. The teacher must recognize signals for needs on the different levels of effects. This means that the emotional appraisal of stressors in voicing is differentiated.

Safety signals in stress-voicing refer to the relationship of voicing with good health and physical wellness. Signals for safety in danger are identified for their potential as noxious invaders or mechanical distress. These are the potential stimuli that can harm the organism and particularly the vocal organs, i.e. the distressors that evoke too high a local arousal reactivity [24] (e.g. unhealthy classroom conditions, lacks in hygiene of the voice, vocal load) as well as the distressors that evoke too high a general arousal reactivity [24] (e.g. lifestyle, general coping style, workload) [22, 24, 41, 46, 49-52]. Safety signals to voicing are often poorly represented in the awareness of (student) professional voice users $[53,54]$.

For example Carl reports: 'Does the teacher have a choice in how to use his/her voice when dealing with a rowdy class, instead of repeatedly overstressing the voice to gain back control of the situation? Also: how to speak to a large group (sometimes of up to 100 students) on a school trip in often less than ideal circumstances (e.g. noisy museums, streets, etc.)?'

"I was never really taught proper "voice hygiene" and the combination of a very demanding job, working in a foreign language, and the often poor acoustic conditions in which I had to work led to me developing some "coping" techniques that proved to be far from optimal.'

Signals for security (in danger) are identified. Ego threat is very plausible to (student) teachers $[38,43]$. This fear is likely to get evoked or increased by the multiple tasks and in association with apprehension of social criticism from students, colleagues and the administration [39].

For example Carl reports: 'As a teacher, I always feel like I am being "observed" and "evaluated": by the students, by the parents, by the school administration, by colleagues, by the general public. I think there are very few professions that are as public as teaching and where people's acts are being judged as much as in education. The moment you walk in the door, there are 20-30 critical observers watching your every move, action, and word (and children or teenagers can be very direct in their judgements).'
Signals for creativity (in danger) are identified. The effects of optimal voicing on the spiritual level are very rewarding; on the other hand, the attitude of service and the expression of one's authenticity are easily gone too, when overwhelmed by fear, when burned out or when extremely preoccupied about needs on the other levels.

For example Carl reports: 'When tired, sick, or emotionally unbalanced, it's a lot harder to stay focused on the class. Especially at the beginning of my career, I have found myself in these circumstances more than once yelling and screaming at a "difficult" class to get them back on task or to reassert my authority. Now I realize that this is not only totally inefficient and counterproductive, it also does a lot of damage to the voice and creates a bad pattern and habit. Moreover, it goes completely against my nature and authenticity and I now recognize it as a (bad!) coping habit.'

Misbalance occurs when disproportional attention is paid to one of the levels safety-security-creativity. It happens on the short and/or on the long term.

\section{Awareness of (Non)-Integrated Coping}

Distortion and restoration of the balance of coping effects belongs to the rhythm of life and belongs to the growing process of a biopsychosocial organism [22, 23]. This balance is a wellspring of vital energy [24]. The moderation and channelling of vital energy produces the optimal force in eustress-euvoicing $[22,23]$. The anticipation of coping can evoke either high excitement or fear [55]. (Dis)balance leads to (lack of) self-confidence.

SHIPS has an impact on the teacher's diversity of tasks and roles. VOCE-T is likely to be a desirable mode of effective coping through affiliation with the challenging situation. Speaking and preparing for speaking is a complex event. It constitutes a field of signals for the teacher's hopeful anticipation of effective vocal communication, or for the fear of ineffective vocal communication $[22,23]$. The crucial pivot is either the inhibition or the freedom to express one's needs and emotions [14, 38, $39,43,49$ ]. A generalized feeling of being (un)skilled to harmonize all of the levels of the basic needs or verbalize can be existentially frightening or fulfilling $[9,34$, $42,43]$.

The memory and the anticipation of these effects (trait) of the voicing behaviour colour the teacher's actual feeling about his/her modes of coping (state). This is especially the case in critical situations. Internal and external stimuli associated with (failure in) coping can become specific signals for challenge (or danger) as well. 
Behavioural analysis has to make this explicit to the student teacher or teacher as a trainee in SHIPS.

For example Carl reports: 'Like most teachers, I can remember classes I dreaded to go to as I knew how challenging they would be. The outcome, invariably, was that at the end of class I was exhausted, both physically as well as mentally. In most cases, it also meant that I focused so much on plain "survival-coping" that the voice suffered badly and that I just reinforced bad voicing techniques; just to maintain law and order.'

Avoidance may show up as a likely reaction. In some circumstances and in the short term, avoidance, either active or passive, might be a rational and adapted reaction to meet needs in danger. Overt avoidance appears to be a less used coping strategy in teachers compared with some other professionals. But also teachers who tend to affiliate instead of passively avoiding might show a defensive coping style. It has to be envisaged in which manner the individual teacher may try to compensate for insufficiencies of the voice. The habitual ways of communicating by voicing are assessed.

Functional analysis looks for conditions at the level of the origin of habits. Habits may have started as reactions to a distressing environment. The feelings about distressors and the attempts to cope have been developed and maintained by reinforcing effects. These original coping behaviours have been seen as successful in their effect on the environment that became less disturbing as a consequence of these behaviours $[19,22,23]$. Such habits may be identified either as the adaptation to bad acoustical conditions such as in classes, sport halls, open air or as the compensation for (occasional) dysfunction of the voice. Defensive attitudes and styles in vocal communication might have originated from having to deal with issues of discipline in the educational context, with parental negativism/criticism, with organizational demands or (non)-collegial actions. Such reactions of 'resistance' to distressors may be maintained as habits in the behaviour repertoire [24]. In teachers, the compensatory changes in pitch, tension, rhythm, articulation, and minor expressivity are illustrative for it. Defensive voicing modes once felt as rewarding may become conditioned as stereotypical ways of responding, even when not functional any more $[22,23]$.

Phenomena of (over)defensive, even struggling coping behaviours are inherent in distress-disvoicing. Vocal misuse may be identified as a non-adapted, maybe as a struggling way of coping. Non-effective defence reactions become rigid and their influence on the behaviour repertoire is expanding [24]. (Over)defensive vocal behaviours are considered to be non-adaptive coping reactions because they harm the vocal apparatus and the voice quality $[22,23,44,54]$. They keep voicing beneath the teacher's desirable limits in being audible, non-tiresome, agreeable, esthetical, and appealing. Because of the counterproductivity of that kind of defence behaviours, they may be identified as a distressor on the three levels of basic needs. In SHIPS, functional analysis, with the focus on VOCE-T, has to point this out.

Doubts about approaching or avoiding a distressing situation are likely to occur. Due to this uncertainty or approach-withdrawal conflict the teacher is apt to develop increased tension. Increased tension is a likely reaction if the teacher evaluates the opportunities or coping abilities to be non-sufficient to meet perceived needs [14]. If neither alternatives to struggle behaviours nor withdrawal are available, the professional communication tasks may be experienced as 'situations of confinement'. These may turn into a critical situation. Various fear-inducing environments may become a common denominator: they elicit the feeling of being trapped and helpless $[14,56]$. Confinement has this common denominator. It may be felt in stage performances, in public speaking, in meetings or at professional social events [22, 23]. It seems to be evident in the classroom and other school-related activities as well. Confinement distress is obvious in the teacher who must adapt to a strict timetable and limited recuperation time [39]. Confinement easily results in increased feelings of tension and fear $[39,56]$. This provokes or sustains distress in vocal communication.

For example Carl reports: 'Yet, teachers are only human too: we are also hungry, tired, sad, happy, frustrated, etc. Sometimes, I envy the manager who can close the door of his office and cancel all of his appointments for the afternoon while he deals with the emotions of his own personal life. Teachers can't cancel their classes or close the door: we're always on the stage, using our voice.'

Confinement may provoke aversive conditioning of a very specific situation. Besides situational aversion developing, the (student) teacher might feel chronically ambiguous about needs that need to be met by communication. This is because elicitors of an approach-withdrawal oscillation are likely to function as critical signals [14]. These may easily get conditioned as distressors to disvoicing.

Failing to cope in vocal communication is potentially highly distressing $[22,23,38]$. The long-lasting perception of basic human needs in danger, owing to suboptimal coping and/or confinement, seems likely to be a critical antecedent of trait distress in teachers $[22,38,52]$. It produces averseness as the basic mood going along with 
vulnerability to physiological dysfunctioning, e.g. hyperactivation, hyperventilation, and tension (table 1). Nonadapted coping habits bring the teacher into an aversive feedback loop of distress and disvoicing. It might become revealed at the development of a generalized feeling of ineffectiveness that is conditioned to a wide field of stimuli. In trait stress, long-lasting aversive signals engender or remember the perceived lack of coping skills. The teacher's effectiveness in the field of communication finds itself in danger chronically and at different levels $[22,23]$.

For example in the case of J.J.: Because of fatigue, professional tasks remain beneath the desirable quality. Disciplinary devices with difficult groups of students are exhausting and moreover hinder building up an empathic relationship. J.J. feels her output of talents in teaching, including the enfoldment of intellectual accuracy, are limited. Because of the fear that her professional capacities are underestimated, J.J. feels tensed in contacts with colleagues and with the students' parents, and on occasions for socializing she feels inhibited. Even though she knows that the chance for loosing her job is not a rational thought, her self-image about commitment to the teachers' task is not rewarding. Nonadaptive use of the voice goes along with physical, even painful efforts as she attempts to compensate for the inconvenience.

Once a defensive distress-disvoicing circle has started up, it appears to be self-sustaining. A basic mood of sadness and discouragement may colour it [14, 57].

Anticipatory anxiety may result from non-optimal coping $[14,55]$. Consciously worrying about coping may be associated with communication situations, which may function as signals for conflict of needs. It is reflected in the approach-withdrawal oscillation. Less spontaneity in the face, in the body, the gestures and the voice may be expressions of it. And these behaviours keep effects of vocal communication restricted or even fully non-adapted. Conscious worrying about non-optimal voicing contains the potential of a chronic mental distressor [22, 23, 30]. Elicitors of an approach-withdrawal oscillation are likely to function as critical signals. Feeling ineffective in coping with basic needs becomes associated with a diversity of signals or conditioned stimuli.

The teacher's anticipation of vocal communication tasks may be defined by the negativism of 'I hope not to fail' [52]. Any object, event, sensation or thought can become conditioned as a distressor. The (non-adapted) voicing act itself contains a potential of critical stimuli by its audible, autonomic, cognitive and motor sensations. The label of 'voicing difficulties' may become connected to feelings of being insufficient in coping. The self-perception of disvoicing in combination with the (self)appraisal of voice deficit becomes a distress provok- ing mental stimulus [58]. The self-perception of lack in effective coping with communication challenges is likely to provoke a feeling of helplessness. In turn, this feeling provokes a fear for non-effective coping abilities and even for the loss of control. This means the anticipation of non-effectiveness makes the (student) teacher feel helpless.

Non-flexibility of habits of vocal compensation and struggling behaviours hinder the voice user from having reality testing with alternate modes of coping. Thus, nonadapted defence habits, developed as a specific coping style in vocal communication, prevent anticipatory anxiety from being changed into hope. Anticipatory anxiety is shown to be self-persistent indeed $[14,16,19]$.

Awareness consists of understanding the characteristic self-generating emotion in teacher's distress-disvoicing. The emotional appraisal of 'having a voice handicap' is enhanced by a negative feedback of bodily sensations, of cognitive disruptions, of emotional harassment of nonproductive struggling and non-effective habits. It may lead to conscious worrying, exhaustion, burning out [22, 23]. Awareness of coping modes by the use of optimal vocalization and expression aims at the appraisal of being voicing skilled.

For example Carl reports: 'One of the first "aha-Erlebnis" I had during the therapy was to learn that no part of the body that we, humans, use for speaking is actually designed for speech. I thought that when I was tired or lost my voice, I just didn't use my "voice" correctly. I hadn't made the connection yet with emotion, physical fatigue.'

\section{Preparedness to a Process of Integrated Change and Self-Control}

From understanding of non-adapted modes of coping and from awareness of potential alternatives in vocal communication [this issue, part 2], a preparedness to integrated change of the entities of SAECE should result. A broad spectrum of integrated attitudes and skills for VOCE-T should become reflected in the self-image of potential control on effective coping. Of course, each candidate trainee may already manifest a great deal of the (potential) capacities to VOCE-T. But a teacher, who encounters critical circumstances as a professional voice user, can anyhow profit from a learning process which reinforces or improves these potential qualities by integration in the whole of (self)appreciated attitudes and skills. The process of change of trait stress is considered as a preventive device in student teachers and starter teachers, ad- 
hering to reducing the vulnerability to state stress. Defining what is (more) desirable as a habit or as an enlarged skill is discussed and decided in common consensus. This is the first step in developing change in the self-regulation competence in SHIPS.

Self-empowering means partially accepting unchangeable factors [59]. It means accepting relative responsibility for updating the potential coping abilities as well [32, 34]. This is the crucial point throughout the integrating process of awareness and change: knowing and experiencing that one has a free choice between some undesirable old habits and more optimal new ones. It is the potential to create change of interrelations between and within the SAECE entities of stress-voicing. It is the core of integrated self-control which is the working agent in the learning process instigated by the twin process of awareness and change. It is essential for the care and cure of the voice by SHIPS, and for eustress prevailing over distress in VOCE-T.

\section{Synthesis}

The aim of this paper was to formulate a strategy of the process of awareness of stress-voicing. It consists of understanding the multiple interactions in SAECE, considered as a dynamic whole, inherent to the waves of life.

The option of the comprehensive model of SAECE for underlying awareness and change in SHIPS seems adequate for enhancing self-consciousness of the teacher as belonging to a group of professionals with a high risk for internal and external stressors.

The teacher becomes aware that maintaining a balance in basic needs is a wellspring of vital energy and that moderation and channelling of vital energy produces the optimal force in eustress-euvoicing. The anticipation of coping (non)-effectively leads to (a lack of) self-confidence. A diversity of stimuli in the internal or external environment associated with perceived needs are apt to function as signals. They are connected to values of survival and physical wellness, interpersonal rewards and existential fulfilment, and are perceived as eustressors or distressors [22, 23].

The (student) teacher as a trainee in SHIPS gets more conscious of these incentives in relation to risks for coping ineffectively and disharmoniously on different areas of well-being. The effects of non-effectively coping in vocal communication may be detrimental to physiological health or discomfort. Among teachers, (non)-effective defence reactions can lead to either doubts or self-assur-

ance about charisma in mental leadership because of (non)-desirable effects of vocal coping. Existential fulfilment can be at risk or reinforced.

Systematic and holistic awareness should motivate the teacher's willingness to grow in the power of self-control on internal and external communicational environments. Awareness in SHIPS has an impact on the teacher's diversity of tasks and roles. The process of awareness results in preparedness to learn VOCE-T that is a mode of effective coping through affiliation with the challenging situation. In the process of awareness and change of attitudes and habits, trainees are guided by the principles of conditioning and reconditioning. Trainees in SHIPS get familiar with excitatory learning, with operant learning, with learning by imitation and with the cognitive learning implied in this. In this way, the teacher tends to become a conscious and active participant in a systematic and holistic process of awareness and of integrative change.

The sharing of the comprehensive model of SAECE has been felt useful to the common understanding of success or failure in handling some tribulations in vocal communication and in the formulation of questions for further discussion and study.

The present part (process of awareness) and the next part (process of change) are descriptions of the method of SHIPS which are intended to provide information to the referrer, trainer and trainee in quest of (self)help in managing stress-voicing.

References

Folia Phoniatr Logop 2010;62:61-70
1 Institute of Medicine: Crossing the Quality Chasm: A New Health System for the 21st Century. Washington, National Academy Press, 2001.

2 Arnold MB: Emotion and Personality. New York, Columbia University Press, 1960, vol 1: Psychological Aspects.

3 Arnold MB: Emotion and Personality. New York, Columbia University Press, 1960, vol 2: Neurological and Physiological Aspects.

4 Bandura A: Vicarious and self reinforcement process; in Glaser R (ed): The Nature of Reinforcement. New York, Academic Press, 1971, pp 228-278.

5 Chambless DL, Sanderson WC: An update on empirically validated therapies. Clinical Psychol 1996;49:5-18.

6 Chambless DL, Baker MJ, Baucoom DH, Beutler LE, Calhoun S, Crits-Cristoph P: Update on empirically validated therapies. Part 2. Clin Psychol 1998;51:3-16.

7 Eelen P, Vervliet B: Conditioning and Anxiety: A Historical Perspective. Washington, American Psychological Association, 2006. 
8 Ellis A, Whiteley JM: Theoretical and Empirical Foundations of Rational-Emotive Therapy. Monterey, Brooks/Cole, 1979.

9 Frankl VE, Frankl VE: Man's Search for Meaning. New York, Washington Square, 1985.

10 Goldfried MR: Reduction of generalized anxiety through a variant of systematic desensitization; in Goldfried M, Merbaum M (eds): Behavior Change through Self-Control. New York, Holt, 1973.

11 Haynes SN: The assessment-treatment relationship and functional analysis in behavior therapy. Eur J Psychol Assess 1998;14:26-35.

12 Hearst E: Fundamentals of learning and conditioning; in Atkinson RC, Herrnstein RJ, Lindzey G, Luce RD (eds): Stevens' Handbook of Experimental Psychology, ed 2. New York, Wiley, 1988, vol 2: Learning and Cognition, pp 3-109.

$\checkmark 13$ Hermans D, Craske MG, Mineka S, Lovibond PF: Extinction in human fear conditioning. Biol Psychiatry 2006;60:361-368.

14 Izard CE: The Psychology of Emotions. New York, Plenum Press, 1991.

15 Kanfer FH, Schefft BK: Guiding the Process of Therapeutic Change. Champaign, Research Press, 1988.

16 Lang PJ: The cognitive psychophysiology of emotion: fear and anxiety; in Tuma AH, Maser JD (eds): Anxiety and the Anxiety Disorder. Hillsdale, Erlbaum, 1985, pp 131-170.

17 Lindsley DB: Emotion; in Stevens SS (ed): Handbook of Experimental Psychology. New York, Wiley, 1951, pp 473-516.

18 Maslow AH: The Farther Reaches of Human Nature. New York, Viking Press, 1971.

19 Mowrer OH: Learning Theory and Behavior. New York, Wiley, 1960.

20 Nezu AM, Nezu CM, Peacock MA, Girdwood CP: Case formulation in cognitive-behavior therapy; in Hersen M, Haynes SN, Heiby EM (eds): Comprehensive Handbook of Psychological Assessment. New York, Wiley, 2004, vol 3: Behavioral Assessment.

21 Norcross JC, Beutler LE, Levant RF: Evidence-Based Practices in Mental Health: Debate and Dialogue on the Fundamental Questions. Washington, American Psychological Association, 2006.

22 Wellens WAR, Van Opstal MJC: Performance stress in professional voice users; in Dejonckere PH (ed): Occupational Voice: Care and cure. The Hague, Kugler, 2001, pp 81-100.

23 Wellens WAR, Van Opstal MJC: A comprehensive model of how the stress chain affects voice; in Izdebski $\mathrm{K}$ (ed): Emotions in the Human Voice. San Diego, Plural Publishing, 2008, vol 2: Clinical Evidence, pp 253-271.

24 Selye H: The Stress of Life, revised ed. New York, McGraw-Hill, 1976.

25 Bandura A: Principles of Behavior Modification. New York, Holt, 1969.
26 Haynes SN, Wiliams AW: Clinical case formulation and the design of treatment programs: matching treatment mechanisms and causal relations for behavior problems in a functional analysis. Eur J Psychol Assess 2003;19:164-174

27 de Jong FI, Kooijman PG, Thomas G, Huinck WJ, Graamans K, Schutte HK: Epidemiology of voice problems in Dutch teachers. Folia Phoniatr Logop 2006;58:186-198.

28 Misterek M, Knothe M, Johannes E, Heidelbach JG, Scheuch K: Studies of voice stress in teachers with functional voice disorders caused by teaching activity. Z Gesamte Hyg 1989;35:415-416.

29 Vilkman E: Occupational risk factors and voice disorders. Logop Phoniatr Vocol 1996; 21:136-141.

30 de Jong FI, Cornelis BE, Wuyts FL, Kooijman PG, Schutte HK, Oudes MJ, Graamans K: A psychological cascade model for persisting voice problems in teachers. Folia Phoniatr Logop 2003;55:91-101.

-31 Goldfried MR: Systematic desensitization as training in self-control. J Consult Clin Psychol 1971;37:228-234.

32 Goldfried MR, Davison GC: Clinical Behavior Therapy. New York, Holt Rinehart and Winston, 1976.

33 Goulding MM, Goulding RL: Changing Lives through Redecision Therapy. New York, Brunner/Mazel, 1979.

34 Hayes SC, Strosahl K, Wilson KG: Acceptance and Commitment Therapy: An Experiential Approach to Behavior Change. New York, Guilford Press, 1999.

35 Selye H: On the real benefits of eustress. Psychol Today 1954;12:60-64.

36 Jones HG: Learning and abnormal behaviour; in Eysenck HJ (ed): Handbook of Abnormal Psychology: An Experimental Approach, ed 1. New York, Basic Books, 1961, pp 488-527.

37 Lindsley DB: Psychophysiology and motivation; in Jones MR, Morgan CT, Lindsley DB, et al (eds): Nebraska Symposium on Motivation. Lincoln, University of Nebraska Press, 1957, pp 44-105.

38 Butcher P, Elias A, Raven R: Psychogenic Voice Disorders and Cognitive Behaviour Therapy. San Diego, Singular Publishing Group, 1993.

39 Martin S, Darnley L: The Teaching Voice. San Diego, Singular Publishing Group, 1996.

40 Lazarus RS: On the primacy of cognition. Am Psychol 1984;39:124-129.

41 Ellis A: Reason and Emotion in Psychotherapy. New York, Stuart, 1962

42 Kolstoe J: Developing Genius. Oxford, George Ronald Publisher Ltd., 1995.

43 Maisel E: Staying Sane in the Art. New York, Putnam's Sons, 1992.
44 Dietrich M, Verdolini Abbott K: Psychobiological framework of stress and voice: a psychobiological framework for studying psychological stress and its relation to voice disorders; in Izdebski K (ed): Emotions in the Human Voice. San Diego, Plural Publishing, 2008.

45 Kimbali CP: Stress, emotions and illness: a problem in biopsychosocial medicine; in Mathew RJ (ed): The Biology of Anxiety. New York, Brunner/Mazel, 1982, pp 187-203.

46 Kobasa SC: Stressful life events, personality, and health: an inquiry into hardiness. J Pers Soc Psychol 1979;37:1-11.

47 Seifert E, Kollbrunner J: Stress and distress in non-organic voice disorder. Swiss Med Wkly 2005; 135:387-397.

48 Seifert E, Kollbrunner J: An update in thinking about nonorganic voice disorders. Arch Otolaryngol Head Neck Surg 2006;132: 1128-1132.

49 Barlet ES, Izard CE: A dimensional and discrete emotions investigation of the subjective experience of emotion; in Izard CE (ed): Patterns of Emotions: A New Analysis of Anxiety and Depression. New York, Academic Press, 1972, pp 129-173.

50 Fecteau S, Armony JL, Joanette Y, Belin P: Judgment of emotional nonlinguistic vocalizations: age-related differences. Appl Neuropsychol 2005;12:40-48.

51 Lazarus RS: Cognitive and coping processes in emotion; in Weiner B (ed): Cognitive Views of Human Motivation. New York, Academic Press, 1974, pp 21-32.

52 Weiner B: An attributional theory of achievement-motivation and emotion. Psychol Rev 1985;92:548-573.

53 Fitzgerald DA, Angstadt M, Jelsone LM, Nathan PJ, Phan KL: Beyond threat: amygdala reactivity across multiple expressions of facial affect. Neuroimage 2006;30:1441-1448.

54 Kooijman PG, de Jong FI, Oudes MJ, Huinck W, van Acht H, Graamans K: Muscular tension and body posture in relation to voice handicap and voice quality in teachers with persistent voice complaints. Folia Phoniatr Logop 2005;57:134-147.

55 Plutchik R: Emotion: A Psychoevolutionary Synthesis. New York, Harper \& Row, 1980.

56 McNally RJ: On 'stress-induced recovery of fears and phobias'. Psychol Rev 1989;96:180181.

57 Plutchik R: The Emotions: Facts, Theories, and a New Model. New York, Random House, 1962.

58 Murry T, Rosen CA: Outcome measurements and quality of life in voice disorders. Otolaryngol Clin North Am 2000;33:905916.

59 Siirala M: Medicine in Metamorphosis: Speech, Presence and Integration. London, Tavistock Publications, 1969. 